\title{
WORK OVERLOAD OF NURSES AND MIDWIVES IN BULGARIAN HOSPITALS AND THE NEED FOR PROVISION OF SUPPORTING CARE BY HEALTH ASSISTANTS
}

\author{
Krasimira Laleva, Lora Georgieva \\ Department of Social Medicine and Health Care Organization, Faculty of Public Health, \\ Medical University of Varna
}

\begin{abstract}
INTRODUCTION: Medical professionals face big problems in providing supporting care. Currently it is delivered by nurses and midwives, a huge challenge in terms of the constant work overload this kind of medical professionals face in Bulgaria.

AIM: The aim is to explore the work overload among nurses and midwives in Bulgarian hospitals and the need for the recruitment of a separate group of additional staff - health assistants for the delivery of supporting care.

MATERIALS AND METHODS: The study was conducted among the medical staff in nine hospitals in five cities of Northeastern Bulgaria. The total number of respondents was 463 including physicians, nurses and midwives. Data about the work overload of nurses and midwives, as well as the need for additional personnel for supporting care was collected by a semi-structured questionnaire. Data was analyzed with IBM SPSS v. 19 - descriptive statistics and non-parametric tests (the Chi-square test was used for analyzing the independence of two categorical data).

RESULTS: Results show that according to the medical staff, nurses and midwives are "permanently" and "frequently" overloaded with work due to the provision of supporting care for patients. There was no statistically significant relationship between "profession" and "work overload" $\left(\chi^{2}=9.188, p=0.163\right)$, i.e. both nurses and midwives are considered as overloaded with work. Almost all respondents notify that medical orderlies also take part in delivering supporting care. Two thirds of the respondents acknowledge the need for hiring health assistants.
\end{abstract}

CONCLUSION: There is an essential need for health assistants in Bulgarian health care. The new health professionals would be fully involved in providing supporting care which would improve quality of care and reduce the work overload of nurses and midwives.

Keywords: work overload, nurses, midwives, supporting care, health assistant

Address for correspondence:

Krasimira Laleva

Faculty of Public Health

Medical University of Varna

55 Marin Drinov Street

9002 Varna

e-mail:krasimiralaleva@yahoo.com

Received: April 7, 2017

Accepted: April 25, 2017

\section{INTRODUCTION}

Supporting care is a quality of care for persons who are not able to independently perform basic daily activities. In hospital settings supporting care includes maintaining personal hygiene, assistance with nutrition, fluid and medication intake, decubitus prevention, assistance with dressing and undressing, daily monitoring of patient, emotional support, etc. (1). 
Many terms are used for identifying persons who provide supporting care (in our country they are known as "caregivers"). In brief, a caregiver is a person who takes care of a patient with a chronic debilitating disease, mental health problems or a sick elderly (2). In a broad sense, the term caregiver is used for individual who cares for someone whose physical abilities are limited due to illness, physical or mental incapacity or due to old age. The broader explanation of this concept includes providing supporting care for pregnant women and newborns.

Basically, caregivers can be classified as formal and informal. The term informal caregiver usually means "voluntary caregiver", "informal carer" and is annotated to a person who takes care of an ill relative or a friend at home. The other term "formal caregiver", also known as "hospital attendant", "healthcare attendant", "nursing auxiliaries" is a professional who provides supporting care in hospital settings and is paid for that. In some countries like the US health assistants who care for people with special needs are known as "mental hospital attendants" or "health assistants of people with mental disabilities" $(3,4)$. Other terms for formal caregiver in a hospital are "medical orderly", "ward assistant", "nurse assistant", etc. In the UK this kind of professionals are known as "carers". They take care of sick elderlies who are not able to perform basic activities. In Canada supporting care is provided by professionals called "caregivers". Their duties include physical and emotional support and help in performing daily activities such as transportation, intravenous administration of drugs, changing a catheter, etc. In the US professionals who deliver supporting care to patients are called "nursing assistants" or "nurse's aides". They are working under the observation of nurses and help patients in performing their daily activities. Most nursing assistants are working at hospitals, nursing homes, etc. where they assist nurses (5). One of the countries with traditions in support care is France. There is a special group of professionals called "caregivers" who deliver supporting care for patients and assist medical staff in hospitals (6).

Activities that formal caregivers perform are the following: washing and changing patient's clothes, accompanying the patient to the toilet or for medical exams, maintaining patient's comfort and physical condition measurement - body tempera- ture, pulse, weight, etc. (7). Health assistants could work in different hospital wards, their duties vary depending on their job specification. For this reason, their duties may be related to calming aggressive patients, transporting patients, preparing patients for operation, etc. Mostly, health assistants are men, because certain tasks require greater stamina and physical force. Usually, healthcare assistants work in emergency departments, psychiatric hospitals, longterm care and orthopedics $(8,9)$.

\section{AIM}

The aim is to explore the work overload among nurses and midwives in Bulgarian hospitals and the need for recruitment of separate group of additional staff - health assistants for the delivery of supporting care.

\section{MATERIALS AND METHODS}

The study was conducted in nine hospitals in Northeastern Bulgaria among medical staff in the following cities: Varna, Shumen, Targovishte, Veliki Preslav and Novi Pazar. The total number of participants was 463 including physicians, nurses and midwives. Information about the assessment of the work overload intensity of nurses and midwives, and the needs for additional personnel for supporting care, was obtained by a semi-structured questionnaire. Data was entered and analyzed with the statistical package IBM SPSS v.19. Statistical tests that were applied include descriptive statistics and non-parametric tests (the Chi-square test was used for analyzing the independence of two categorical data).

\section{RESULTS AND DISCUSSION}

Results represent the intensity of work overload of nurses and midwives and the need for additional supporting care staff in different hospital wards.

Due to the specifics in the duties of midwives in obstetrics and gynecology wards, the overall data were separated as follows: for medical doctors and nurses $(\mathrm{n}=390)$ and for medical doctors and midwives $(\mathrm{n}=73)$.

General results about the opinion of medical doctors and nurses $(n=390)$ about work overload of nurses in hospital departments is presented in Figure 1. More than half of the respondents - 208 
(53.33\%), indicated work overload as "permanent" and a significant share of the participants have designated it as "frequent" - 150 (38.46\%). The permanent and frequent intensity of work overload among nurses is due to the larger psycho-emotional stress and physical strain of nurses. A small majority of respondents define work overload as "seldom" 20 (5.13\%) and "never" - 12 (3.08\%).

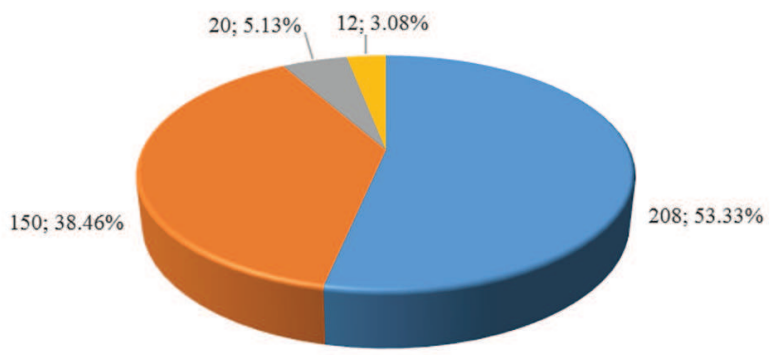

MPermanently $M$ Frequently $\triangle$ Seldom 1 Never

Figure 1. Work overload of nurses according to nurses and physicians $(n=390)$

The study results present a very high activity of medical orderlies in the delivery of support care to patients (Figure 2). According to most respondents, medical orderlies "permanently" (170 - 43.59\%) or "frequently" (170 - 43.59\%) take part in support care delivery. A small part of them responded that medical orderlies "seldom" (41-10.51\%) or "never" take part $(9-2.31 \%)$ in the provision of support care. Most medical orderlies provide support care to patients in severe postoperative or acute conditions who are not able to take care of themselves. Some activities that

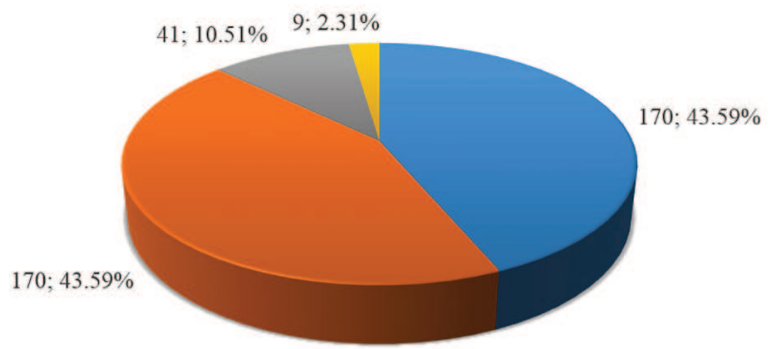

$\square$ Permanently $\square$ Frequently $\square$ Seldom $\square$ Never

Figure 2. Participation of medical orderlies in the delivery of supporting care to patients in hospitals according to nurses and physicians $(n=390)$ medical orderlies perform for patients are: assistance with transportation, nutrition, dressing, etc. It is important to note that the duties of the medical orderly professional should not include supporting care of patients. They are responsible only for the maintenance of hygiene in hospital wards. Their duties are related solely to cleaning and disinfection of the hospital, replacing of bed linen, preparing the bed after patients' discharge and disposal of hazardous waste.

The survey results among midwives and physicians in obstetrics and gynecology wards showed similar results to those among nurses and physicians in other hospital wards. According to most respondents, midwives are "frequently" (38; $52.05 \%)$ and "permanently" (32; 43.84\%) overloaded in the performance of their duties and supporting care is a part of their duties (Figure 3).

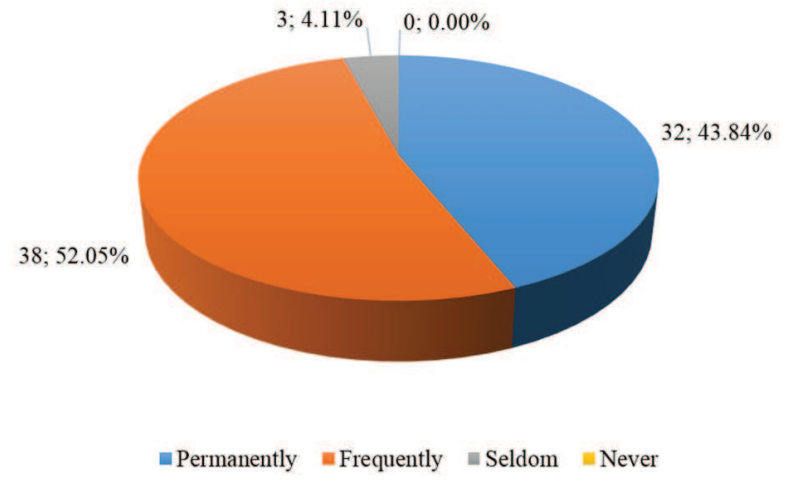

Figure 3. Work overload of midwives according to physicians and midwives $(n=73)$

Because of the "permanent" and "frequent" work overload of midwives, medical orderlies quite often are involved in the delivery of supporting care to patients. Medical orderlies "permanently" take part in supporting care for patients according to 23 (31.5\%) of respondents. Half of them answered that medical orderlies "frequently" take part in support care and few of them responded "seldom" $(6 ; 8.22 \%)$ and "never" - (1; 1.37\%) (Figure 4).

Results from both inquiries among physicians and nurses and among physicians and midwives show that medical orderlies take part in supporting care of patients. Support care is not included in the job description they have to perform. The participation of medical orderlies in caring for the sick can lead 


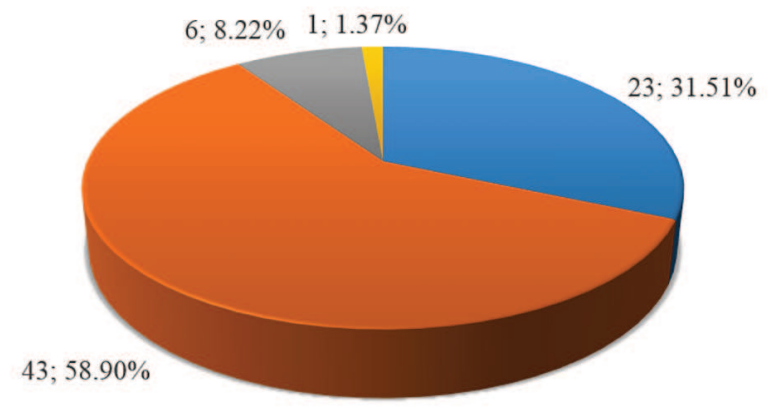

$\square$ Permanently $\square$ Frequently $\square$ Seldom $\square$ Never

Figure 4. Participation of medical orderlies in the delivery of supporting care to patients in hospitals according to midwives and physicians $(n=73)$

to adverse changes in the health status of patients, as they do not have the necessary experience and knowledge. It is therefore imperative to hire welltrained health professionals who would take care of patients, mothers and newborns and relieve the work overload of midwives and nurses as well as avoid the additional involvement of medical orderlies.

The results for the overall work overload of nurses and midwives according to the opinion of medical professionals are represented in Table 1 . Chi-square $\left(\chi^{2}\right)$ test was applied to find out whether the respondents' profession influences their opinion about work overload. There was no statistically significant relationship between "profession" and "work overload" $\left(\chi^{2}=9.188, \mathrm{p}=0.163\right)$. According to the results, nurses and midwives consider themselves as overloaded by work, which is also acknowledged by physicians. In addition to their work responsibilities, health care professionals are responsible for delivering supporting care to patients as a part of their duties.
Results from the study of the opinion of the medical staff about the "need for health assistants" and "work overload of nurses and midwives" show that the need for hiring additional staff depends on the work overload of nurses and midwives $\left(\chi^{2}=17.77\right.$, $\mathrm{p}=0.001)$. About two thirds of the respondents (75.16\%) acknowledge that there is a need for hiring health attendants in order to overcome the permanent and common "work overload" in different hospital departments.

Almost three-fourths of the nurses (78.3\%) appeal for a greater need of additional medical staff (health assistants) apart from medical doctors $\left(\chi^{2}=18.4, p=0.001\right)$. Recruitment of assisting hospital personnel should relieve the work overload of nurses in different wards. Health assistants should perform the following activities: maintaining patients' hygiene, assistance with nutrition and fluid intake, assistance with dressing and undressing, assistance with moving and decubitus prevention, etc. Half of the midwives (53.7\%) call for the need of health assistants in gynaecological departments. Health assistants should help midwives in gynecological care for female patients with inflammatory diseases, precancerous, benign neoplasms and other diseases, which require continuous monitoring. This type of professionals should be aware of diseases' risks and they have to provide supporting care for gynecologically ill women in hospital. Future specialists should help women with gynecological disease perform basic activities like assistance with nutrition and fluid intake, assistance in transportation and decubitus prevention, etc. Health professionals in supporting care should also assist mothers with breastfeeding and daily care for newborns. Some of the skills that health assistants should have are swaddling babies, changing diapers, etc.

Table 1. Work overload of nurses and midwives, according to the medical staff $(n=463)$

\begin{tabular}{|c|c|c|c|c|c|}
\hline \multirow{2}{*}{$\begin{array}{l}\text { Opinion by profession } \\
\text { of respondents }\end{array}$} & \multicolumn{4}{|c|}{ Work overload intensity of nurses and midwives } & \multirow{2}{*}{ Total } \\
\hline & Permanent & Frequent & Seldom & Never & \\
\hline Nurse & $159(54.8 \%)$ & $106(36.6 \%)$ & $17(5.9 \%)$ & $8(2.7 \%)$ & 290 \\
\hline Midwife & $29(43.3 \%)$ & $35(52.2 \%)$ & $3(4.5 \%)$ & $0(0.0 \%)$ & 67 \\
\hline Medical doctor & $52(49.1 \%)$ & $47(44.3 \%)$ & $3(2.8 \%)$ & $4(3.8 \%)$ & 106 \\
\hline Total & $240(51.8 \%)$ & $188(40.6 \%)$ & $23(5.0 \%)$ & $12(2.6 \%)$ & 463 \\
\hline
\end{tabular}


Work Overload of Nurses and Midwives in Bulgarian Hospitals and the Need for Provision of Supporting Care By Health Assistants

\section{CONCLUSIONS}

Results from both inquiries show that nurses and midwives are overwhelmed when performing supporting care for patients. For this reason medical orderlies are involved in the delivery of supporting care. It is inconsistent with the duties they must perform included in their job description. The participation of medical orderlies in supporting care may lead to adverse changes in the health status of patients, because they do not have the necessary experience and knowledge for the delivery of supporting care. Therefore, there is an essential need to hire hospital attendants in Bulgarian hospitals in regard to the high work overload of nurses and midwives. This can both facilitate the work of health care staff and improve the quality of supporting care for patients in hospitals. It is imperative for health care managers to include health attendants as a part of the health care system.

\section{REFERENCES}

1. Supporting Care 2012 [Internet]. London [cited 2017 Feb 28] (http://www.supportingcare.co.uk/)

2. United Hospital Fund- Next Step in Care [Internet]. New York: Next step in care; 2013, [cited 2017, Feb 28]. UHF Family Caregivers and health Care professionals Working Together (http://www. nextstepincare.org/)

3. Holland JL, Rowe FB, Roath FL, Stone BG. Hospital attendant selection. Nursing Research. 1960; 9(2): 104.

4. McConvey MM. A study of Some Characteristics of Mental Hospital Attendants. A Thesis Submitted to the faculty of the Graduate School of Loyola University in Partial Fulfillment of the Requirements for the Degree Master of Arts, 1960. (http://ecommons.luc.edu/luc_theses/1632).

5. Kentucky Community \& Technical College System [Internet]; Kentucky, USA: Online Nurce Aide Certificate, Learn on Demand [cited 2017, Feb 28] (http://learnondemand.kctcs.edu/en/What_We_ Offer/NAAProgram.aspx).

6. Groupe Hospitalier Saint-Augustin [Internet] Malestroit, France: Training and research [cited 2017, Feb 28] (http://www.ghsa.fr/en/ training-search).
7. Hospital Attendant. Classification Standard. [Internet]. [cited 2017 Feb 28] (http://www.who.int/ $\mathrm{hrh} /$ statistics/Health_workers_classification)

8. Bailey S, Scales K, Lloyd J. The emotional labour of health-care assistants in inpatient dementia care. Ageing and Society. 2015; 35(02): 246-69. doi: 10.1017/S0144686X13000573

9. Gresham T. Attendant Vs. Orderly 2015. [Internet]. [cited 2017 Feb 28] (http://work.chron.com/ attendant-vs-orderly-23097.html). 